\title{
Differential Expression of KCNQ4 in Inner Hair Cells and Sensory Neurons Is the Basis of Progressive High-Frequency Hearing Loss
}

\author{
Kirk W. Beisel, ${ }^{1}$ Sonia M. Rocha-Sanchez, ${ }^{1}$ Ken A. Morris, ${ }^{1}$ Liping Nie, ${ }^{3}$ Feng Feng, ${ }^{1}$ Bechara Kachar, ${ }^{2}$ \\ Ebenezer N. Yamoah, ${ }^{3}$ and Bernd Fritzsch ${ }^{1}$ \\ ${ }^{1}$ Department of Biomedical Sciences, Creighton University, Omaha, Nebraska 68178, ${ }^{2}$ Section on Structural Cell Biology, National Institute on Deafness and \\ Other Communication Disorders, National Institutes of Health, Bethesda, Maryland 20892, and ${ }^{3}$ Department of Otolaryngology, Center for Neuroscience, \\ University of California, Davis, California 95616
}

\begin{abstract}
Human KCNQ4 mutations known as DFNA2 cause non-syndromic, autosomal-dominant, progressive high-frequency hearing loss in which the cellular and molecular basis is unclear. We provide immunofluorescence data showing that Kcnq4 expression in the adult cochlea has both longitudinal (base to apex) and radial (inner to outer hair cells) gradients. The most intense labeling is in outer hair cells at the apex and in inner hair cells as well as spiral ganglion neurons at the base. Spatiotemporal expression studies show increasing intensity of KCNQ4 protein labeling from postnatal day 21 (P21) to P120 mice that is most apparent in inner hair cells of the middle turn. We have identified four alternative splice variants of Kcnq4 in mice. The alternative use of exons 9 -11 produces three transcript variants (v1-v3), whereas the fourth variant (v4) skips all three exons; all variants have the same amino acid sequence at the C termini. Both reverse transcription-PCR and quantitative PCR analyses demonstrate that these variants have differential expression patterns along the length of the mouse organ of Corti and spiral ganglion neurons. Our expression data suggest that the primary defect leading to highfrequency loss in DFNA2 patients may be attributable to high levels of the dysfunctional Kcnq4_v3 variant in the spiral ganglion and inner hair cells in the basal hook region. Progressive hearing loss associated with aging may result from an increasing mutational load expansion toward the apex in inner hair cells and spiral ganglion neurons.
\end{abstract}

Key words: potassium channel; Kcnq4; inner ear; hair cells; progressive high-frequency hearing loss; immunofluorescence; quantitative RT-PCR

\section{Introduction}

Both high- and low-frequency progressive hearing loss represent a wide diversity of gene mutations that are observed in a large number of syndromic and non-syndromic diseases (Petit et al., 2001). Inherited hearing loss genes can be classified into three groups: (1) stereocilia-based mechanoelectrical transduction, (2) $\mathrm{K}^{+}$recirculation, and (3) the compositional integrity and function of basement membranes (Steel and Kros, 2001; Beisel et al., 2004). Deafness as a result of the loss of endocochlear potential via disruption of $\mathrm{K}^{+}$recirculation is associated with the connexins (GJB2, GJB3, and GJB6) and the KCNQ1, KCNE1, and Slc12a2 (NKCC1, Na-K-2Cl cotransporter) genes (Tyson et al., 1997; Delpire et al., 1999; Dixon et al., 1999; Flagella et al., 1999). Such dysfunctional channels are localized in structures other

Received May 25, 2005; revised Aug. 19, 2005; accepted Aug. 21, 2005.

This work was supported in part by National Institutes of Health Grants R01 DC05009, DC04279, and DC07592 and by the National Organization of Hearing Research. We thank Richard Hallworth for comments and advice on this manuscript. We are also grateful for the technical assistance of Christine H. Halgard, Lilian Calisto, and Alexis Poduska. The confocal microscopic system was made available by the Nebraska Center for Cell Biology at Creighton University.

Correspondence should be addressed to Dr. Kirk W. Beisel, Department of Biomedical Sciences, Creighton University, School of Medicine, 2500 California Plaza, Omaha, NE68178. E-mail: beisel@creighton.edu.

D0I:10.1523/JNEUROSCI.2110-05.2005

Copyright $\odot 2005$ Society for Neuroscience $\quad$ 0270-6474/05/259285-09\$15.00/0 than the sensory neurons or hair cells. For example, Kcc4 is restricted to the supporting cells, and $\mathrm{Kcc}^{-/-}$mice are nearly deaf within 1 week after the onset of hearing (Boettger et al., 2002). Mutations of voltage-gated potassium channel KCNQ4 cause non-syndromic DFNA2, which is an autosomal-dominant, progressive high-frequency hearing loss (PHFHL) that was categorized as a $\mathrm{K}^{+}$recirculation gene defect (Kubisch et al., 1999).

Conflicting mechanisms of KCNQ4-mediated PHFHL are proposed based on Kcnq4 expression patterns. These are (1) a disruption of $\mathrm{K}^{+}$recirculation at the level of hair cells (Kubisch et al., 1999; Jentsch, 2000; Kharkovets et al., 2000), (2) a dysfunctional central auditory afferent signal transmission (Kharkovets et al., 2000), or (3) dysfunctional basal inner hair cells (IHCs) and spiral ganglion neurons (SGNs) (Beisel et al., 2000). KCNQ4 channels are represented by $\mathrm{M}$-type conductances and are the linopiridine-sensititve $I_{\mathrm{K}, \mathrm{n}}$, present in IHCs and outer hair cells (OHCs), and the vestibular type I hair cell $I_{\mathrm{K}, \mathrm{L}}$ (Kros et al., 1998; Marcotti and Kros, 1999; Marcotti et al., 2003; Oliver et al., 2003; Wong et al., 2004). KCNQ4-mediated PHFHL is unlikely to function in global $\mathrm{K}^{+}$recirculation, because expression is restricted to the neurosensory inner ear epithelium. Therefore, KCNQ4 pathogenesis is unlikely to be mediated by defective $\mathrm{K}^{+}$recirculation. 
Mouse Kcnq4 was localized initially to the OHCs of the inner ear, suggesting that the cochlear pathophysiology is attributable to dysfunctional OHCs (Kubisch et al., 1999). Yet, OHC dysfunction does not provide a plausible explanation for deafness or the progressive nature of PHFHL (Beisel et al., 2000; Oliver et al., 2003). In this study, we undertook further characterization of the distribution of the KCNQ4 protein and related this to expression profiles of various Kcnq4 alternatively spliced variants. Here, we identify four different alternative splice variants of Kcnq4 and their differential distribution in hair cells and the SGNs. We observed opposing longitudinal gradients in the cochlear neurosensory epithelium. The highest expression of KCNQ4 in IHCs and SGNs was in the base hook region, whereas the highest expression levels in OHCs was in the apical turn. These differences suggest that the KCNQ4 defect relates to dysfunctional basal IHCs and/or SGNs. In contrast, the expression in OHCs does not correlate with pathogenesis in PHFHL.

\section{Materials and Methods}

Animal and tissue preparation. As described previously (Beisel et al., 2000), inner ears from semi-outbred CF1 mice were prepared and fixed in 4\% paraformaldehyde (PFA) and decalcified with $150 \mathrm{~mm}$ EDTA in $4 \%$ PFA. After sufficient decalcification, the cochlea was dissected from the inner ear. Removal of the tectorial and Reissner's membranes and the stria vascularis improved probe access to the hair cells. Total RNA was obtained from freshly dissected cochleae and cochlear fractions using RNAlater and RNAqueous (Ambion, Austin, TX) (Morris et al., 2005). The organ of Corti was further dissected by separating the IHCand OHC-containing fragments at the tunnel of Corti. Basal IHCs were obtained by isolating of the very basal tip of the hook region that contains only IHCs. Isolation of IHC and OHC fragments was verified by reverse transcription (RT)-PCR using primers for otoferlin, an IHC marker, and prestin, an OHC marker (Judice et al., 2002).

RT-PCR and quantitative RT-PCR analysis of mouse Kcnq4 expression. Mouse Kcnq4 primers were derived primarily from the mouse Kcnq4 cDNA sequence [clone F930013D18 (Beisel et al., 2004)] as well as mouse genomic sequences. Quantitative RT-PCR (QPCR) primers and probes were designed using PrimerExpress (Applied Biosystems, Foster City, CA), whereas all other primers were designed using Oligo 4.0 (Molecular Biology Insights, West Cascade, CO) (Table 1). Total RNA was prepared, and genomic DNA contamination was eliminated using RNase-free DNase treatment. Positive controls consisted of cDNA templates derived from brain and in vitro transcription of cloned full-length Kcnq4 variants. RT-PCRs and 5' and 3' rapid amplification of cDNA ends (RACE) analyses were also performed on total RNA from mouse tissues or organs obtained either commercially (Clontech, Palo Alto, CA) or from dissected fractions of the mouse cochlea. Approximately $100 \mu \mathrm{g}$ of total or polyA $^{+}$RNA (Clontech) was reverse transcribed using SuperScriptase II (Invitrogen, Carlsbad, CA) and a T7-oligo-dT primer (Beisel et al., 2000) and the addition of a $5^{\prime}$ primer as per the manufacturer's protocol (Invitrogen). Primary PCRs were performed in an MJR thermocycler using 2.5 U of Taq Polymerase (Roche Applied Science, Indianapolis, IN) and $1: 25$ of the cDNA preparation, and 35 cycles $\left(94^{\circ} \mathrm{C}\right.$ for $30 \mathrm{~s}, 50-55^{\circ} \mathrm{C}$ for $30 \mathrm{~s}$, and $72^{\circ} \mathrm{C}$ for $3.5 \mathrm{~min}$ ) were used. Secondary and tertiary amplifications were done using nested primers and $1-2 \mu \mathrm{l}$ of the previous PCRs, and 30 cycles $\left(94^{\circ} \mathrm{C}\right.$ for $30 \mathrm{~s}, 50-55^{\circ} \mathrm{C}$ for $30 \mathrm{~s}$, and $72^{\circ} \mathrm{C}$ for $1.5-2.0 \mathrm{~min}$ ) were used. PCR products were verified by direct sequence analyses using a CEQ 8000 Sequencer (Beckman Coulter, Fullerton, CA) and the thermosequencing ABI Prism Big Dye Terminator kit following the manufacturer's suggested protocol. Promoter analysis of the Kcnq4 gene was done using the following software programs: regulatory Vista (http://genome. lbl.gov/), McPromoter MM:II (http://genes.mit.edu/McPromoter. html), TFSEARCH (http://www.cbrc.jp/research/db/TFSEARCH.html), and WWW Promoter Scan (http://thr.cit.nih.gov/molbio/proscan/).

Cloning of the murine Kcnq4 alternative splice variants. The resulting PCR products were gel purified, blunt-ended using T4 polymerase, and ligated into the HincII site of a modified $\mathrm{pBS}^{+/-}$phagemid vector (Stratagene, La Jolla, CA). The PCR-derived fragments as well as the subsequent cloned fragments were sequenced. Splice variants were examined using the protein identification and characterization programs of ExPASy Proteomics tools (http://us.expasy.org/tools/) for tertiary structures (3Djigsaw; http://www.bmm.icnet.uk/ 3djigsaw/) and posttranslational modification predictions.

Whole-mount immunodetection and microscopic imaging. Analyses were performed on inner ear tissues using the procedures of Fritzsch et al. (1997) for immunofluorescence and Barritt et al. (1999) for immunohistochemistry. Myo7a antibodies and affinity-purified antibodies to KCNQ4 peptides PVHEDISVSAQC ( $\mathrm{N}$ terminus) and SISRSVSTNMD (C terminus) were used. A confocal system (Radiance 2000; Bio-Rad, Hercules, CA) mounted on a Nikon (Melville, NY) Eclipse 800 microscope permitted imaging of Alexa-conjugated secondary antibodies (Molecular Probes, Eugene, OR). The resulting data were morphometrically analyzed using ImagPro software (Media Cybernetics, Silver Spring, $\mathrm{MD})$.

\section{Results}

Tissue distribution of Kcnq4 splice variants

Initial studies showed a restricted expression of Kcnq4 in the central and peripheral auditory systems (Kubisch et al., 1999; Kharkovets et al., 2000). These cDNAs were derived from the midbrain, diencephalon, embryo, head, lung, mammary gland, 


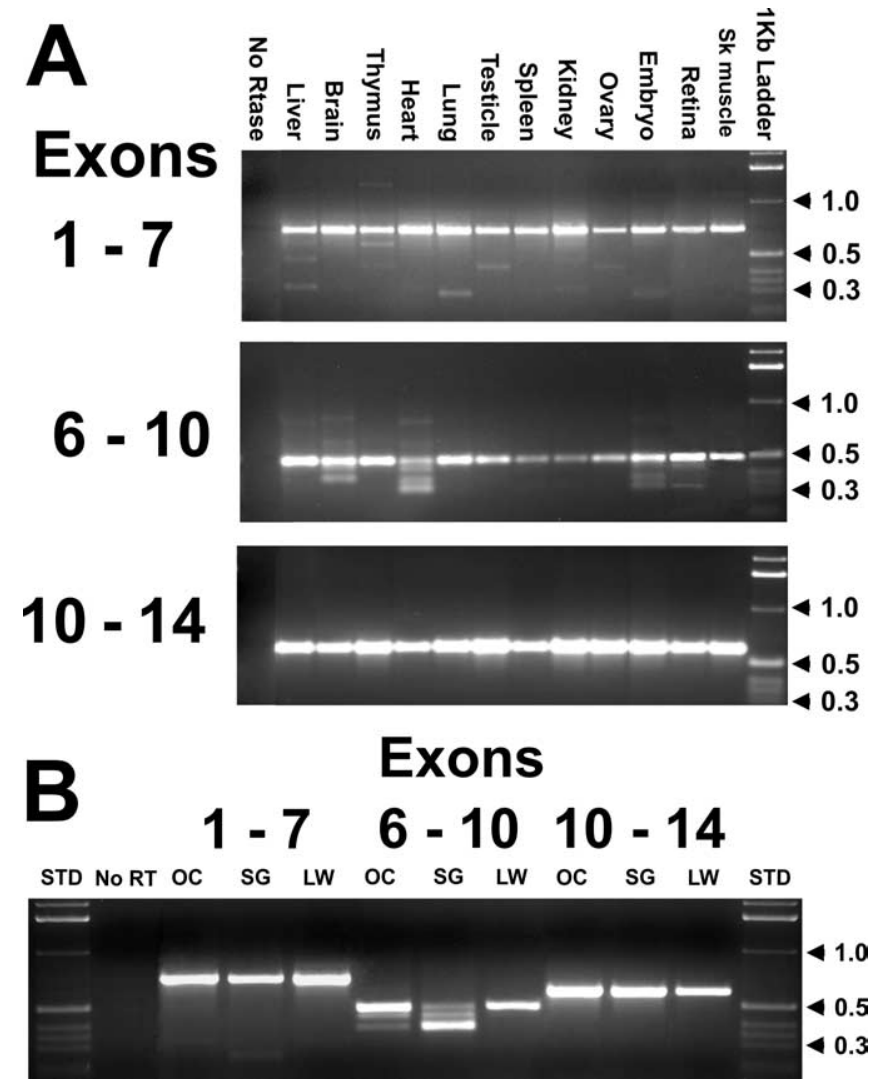

Figure 1. Alterative splicing and tissue distribution. RT-PCR analyses of $K c n q 4$ expression were performed using total RNA preparations from a panel of tissues $(\boldsymbol{A})$ and dissected fragments $(\boldsymbol{B})$ of the inner ear representing the organ of Corti $(O C)$, spiral ganglion (SG), and the cochlear lateral wall (LW). The generation of alternative splice variants was examined by three overlapping PCR products representing exons 1-7, 6-10, and 10-14. A 1 kb ladder (Invitrogen) was used as a standard size marker (STD), and the corresponding kilobase lengths are indicated. Sk muscle, Skeletal muscle.

medulla oblongata, ovary, oviduct, thymus, and urinary bladder libraries. However, at least 21 expressed-sequence tag clones carry the 3' end sequence of Kcnq4 (UniGene Cluster Mm.249977). Using RT-PCR, we found a wider tissue distribution pattern (Fig. 1) than originally reported (Kubisch et al., 1999; Kharkovets et al., 2000). This suggested that Kcnq4 is not restricted to the auditory system but is likely ubiquitously expressed. Differences in the published human KCNQ4 sequences in the GenBank database suggested the existence of at least two alternative splice variants. This warranted further study to determine the extent of splicing. Both $5^{\prime}$ and $3^{\prime}$ RACE analyses were unable to identify alternative forms at either end of the Kcnq4 transcript. However, through the use of exon-specific primers, amplification of overlapping cDNA fragments, and sequence analyses, multiple internal splice variants were detected. Four variants were identified and designated as Kcnq4_v1-v4, based on the predicted kilodalton sizes of the deduced peptides. They differed through alternative use of exons 9-11 (Kcnq4_v1-v3) or by skipping these three exons (Kcnq4_v4). Splice variant Kcnq4_v1, the National Center for Biotechnology Information (NCBI) reference sequence, appeared in all tissues examined (Fig. 1). The other alternatively spliced variants, Kcnq4_v2 and Kcnq4_v3, do appear to have more of a tissue-restricted pattern. Multiple Kcnq4 alternative splice forms were observed in electrically excitable tissues, such as the brain, skeletal muscle, heart, retina, and the inner-ear organ of Corti and spiral ganglion. Kcnq4_v1 and
Kcnq4_v4 [skipped exons 9-11 $(\Delta 9-11)]$ were the predominant forms in the heart and brain, and both of these tissues appeared to have additional splice forms. Variants Kcnq4_v2 and Kcnq4_v4 were predominantly present in electrically excitable tissues. For the most part, Kcnq4_v3 appeared to be limited to the sensory epithelium of the cochlea. It must be recognized that using nested PCR and splice variant-specific primers is a more robust and sensitive assay system, and the presence of all four variants was detected regardless of the tissue source. This was demonstrated by the detection of the Kcnq4_v4 transcripts in SGNs (Fig. $1 B$ ).

Genomic analyses using NCBI genomic BLAST (Basic Local Alignment Search Tool; http://www.ncbi.nlm.nih.gov/genome/ seq/MmBlast.html) showed the presence of three exons, designated as exons 9-11. Each exon exhibited the appropriate $5^{\prime}$ and $3^{\prime}$ splice signals, and their chromosomal locations are depicted in Figure $2 \mathrm{~A}$. Examination of human and rat genomic sequences also showed the presence of these additional exons. The deduced amino acid sequences for these splice variants are depicted in Figure $2 B$ and all are in frame leaving the remainder of the KCNQ4 C-terminus sequence of these proteins unchanged. Using a variety of computer analytical programs for transcription start sites and regulatory element motifs, further assessment of the $\sim 51.1 \mathrm{~kb} \mathrm{Kcnq4}$ genomic sequence indicates the promoter region and upstream transcription regulatory elements are just upstream of exon 1. Comparison of mouse, rat, and human sequences showed sequence conservation within this region. The predicted CAAT and TATA boxes were $\sim 199 \mathrm{bp}$ upstream from a Kozak site containing the predicted translational start site. The majority of regulatory sequence motifs extend up to $\sim 5 \mathrm{~kb}$ upstream from the TATA box, but additional experiments are needed to elucidate the Kcnq4 promoter region.

\section{Quantitative differences in Kcnq4 transcript expression along} the length of the cochlea

As shown in Figure $1 B$, there is a differential use of the splice variants in the three functional components of the cochlea with the principal splice variant, Kcnq4_v1, being expressed in all three cochlear fractions in 5- to 6-week-old mice. Two RT-PCR approaches were used to qualitatively identify the use of the splice variants in the dissected organ of Corti and spiral ganglion. Kcnq4 expression in the organ of Corti was assumed to be restricted to hair cells, because we were unable to detect Kcnq4 transcripts in the nonsensory cells (Beisel et al., 2000). Our primary comparisons were between samples derived from the apex and the base (summarized in Table 2). An apical to basal differential expression was observed by RT-PCR using the exon 6-10 primer set in splice variant utilization, with Kcnq4_v1 being the prevalent variant in the apex and Kcnq4_v3 being the predominant variant in the base (Fig. $3 A$ ). Using splice variant-specific primers, all four splice variants were detected, regardless of location, as shown in Figure 3B. Kcnq4_v1-v3 splice variants were amplified from the organ of Corti, spiral ganglion, and IHC- and OHC-containing fragments, with the principal splice variant, Kcnq4_v1, being predominantly in the apex; Kcnq4_v3 was the major variant in the basal hook region. The Kcnq4_v3 splice variant expression was restricted primarily to the inner ear hair cells and SGNs. Kcnq4_v3 transcript levels based on QPCR were 10-20 times higher in the SGNs at the base compared with the apical SGNs or the organ of Corti samples derived from either the base hook region or the apical turn. This variant was not detected by RTPCR in other tissues. Using QPCR, we were able to verify the differential quantitative use of the different splice variants in the apex and basal hook region (Fig. 3C). In general, Kcnq4_v2 was 
expressed in a lower amount compared with either the Kcnq4_v1 or Kcnq4_v3 variants and represented a minor variant. Kcnq4_v4 transcript levels, which were not obvious by the RT-PCR using the exon 6-10 primer set, were just becoming detectable after 55-60 amplification cycles of the QPCRs in all dissected samples.

\section{Spatiotemporal regulation of Kcnq4}

The developmental progression of KCNQ4 protein expression was examined next. Our previous whole-mount in situ hybridization (wmISH) studies had shown a longitudinal expansion of expression, progressing from the cochlear base to the apex (Beisel et al., 2000; Beisel and Fritzsch, 2003). We also observed similar longitudinal expression in the KCNQ4 protein that paralleled the increase of transcript (Fig. 4A). In general, expression was observed initially around embryonic day 18.5 (E18.5) in the base and preceded longitudinally toward the apex. The IHC expression leads the wave of upregulation, followed by the first row of $\mathrm{OHC}$ and the next two rows of OHCs. At postnatal day 8 (P8), the basal hook region showed the adult expression pattern, and the developmental upregulation had reached the apical turn. At P21, all hair cells, except those in the apical tip, had acquired the adult pattern that was fully obtained by P35. RT-PCR analysis (Fig. $4 B$ ) showed that transcripts could be detected initially in the cochlea at E16.5 but was below the level of detection of both wmISH and whole-mount immunodetection assay systems. In E18.5 cochleae, both ISH and immunodetection could detect Kcnq4 expression in the cochlear base, but it was just above background level thresholds (data not shown). The Kcnq4_v1 splice variant was the predominant form in the developing cochlea, whereas the other splice variants became apparent at P10 just before the onset of hearing in mice (Pujol et al., 1998). Very little, if any, Kcnq4_v4 variant transcripts were observed in the cochlea at all time points examined. These RT-PCR profiling data suggest that the splice variants KCNQ4_v1-v3 may play a physiological role in hearing.

\section{Differential distribution in inner ear hair cells and} ganglion neurons

Our previous wmISH data suggested quantitative differences between the apex and base in the neurosensory epithelium (Beisel et al., 2000). We have confirmed these observations using wholemount immunofluorescence of P21 rat and mouse cochleae. Using affinity-purified rabbit antibodies against KCNQ4 $\mathrm{N}$ - and C-terminal peptides, we examined the adult cochlear expression patterns (Fig. 5). There were no differences observed when using either antiserum alone or in combination. These antibodies recognize all KCNQ4 splice variants because neither the $\mathrm{N}$ - nor C-termini amino acid sequences vary among the four alternative splice forms. Similar basal $>$ apical longitudinal gradients were observed in IHCs and SGNs, and an opposing KCNQ4 gradient

\section{Chromosome 4}
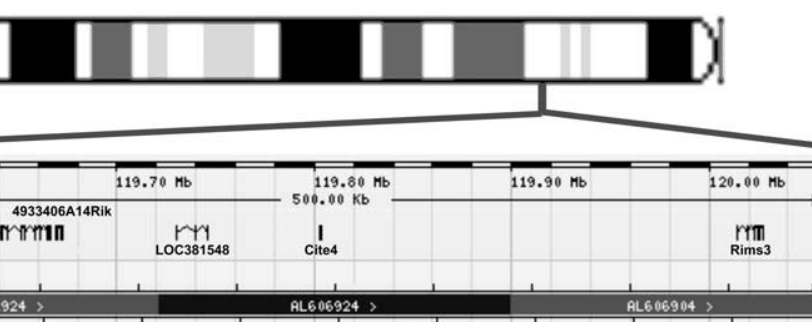

rims

\section{KCNQ4 transcript variants}

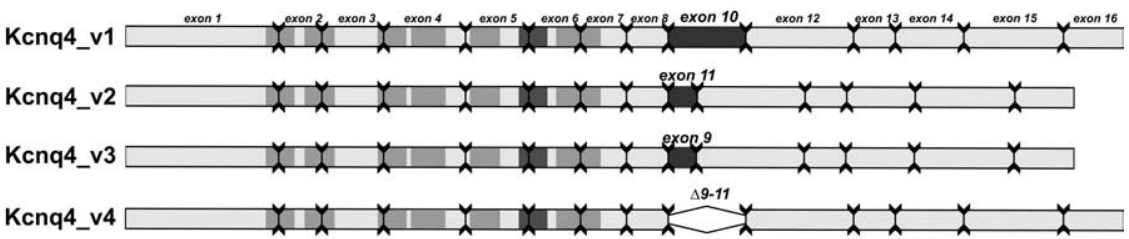

\section{KCNQ4 1}

Amino Acid Sequence

\section{DGAPSRYPPVATCHRPGSASFCPGESSRMGIKDRIRISSSQ \\ AYLTATWYYYDSILPSFRELALLFEHIQRARNGGLRPLEVRRAPVP} AYLATWYYYDSILPSFSOMFSNKRSFFRIHASWRPSSRMGIKD

\section{KCNQ4_v3 AYLTATWYYYDSILPSFSWREEEAAGPRCLSLSSRMGIKDRIRISSSQ}

KCNQ4_v4 AYLTATWYYYDSILPSF*SSRMGIKDRIRISSSQ

Figure 2. Mouse Kcnq4 genomic organization and deduced amino acid sequence of the four splice variants. $\boldsymbol{A}$, The chromosomal location, genomic organization of the 16 Kcnq4 exons, and three alternate exons $9-11$ (black). The four alternatively spliced

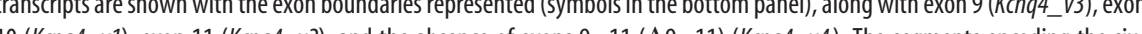
membrane-spanning motif (light gray) and the pore motif (dark gray) are indicated. $\boldsymbol{B}$, The deduced amino acid sequences of and adjacent to exon 9 for each of the four protein KCNQ4 variants. The asterisk demarks the skipped exons 9-11 within the KCNQ4_v4 variant sequence.

Table 2. Expression of Kcnq4 alternative splice variants in P21 mouse cochlea

\begin{tabular}{lllll}
\hline & \multicolumn{4}{c}{ Kenq4 variant } \\
\cline { 2 - 5 } Tissue & v1 & v2 & v3 & v4 \\
\hline Spiral ganglion-apex & $\mathrm{x}$ & $\mathrm{x}$ & $\mathrm{x}$ & $\mathrm{x}$ \\
Spiral ganglion-base & $\mathrm{x}$ & $\mathrm{x}$ & $\mathrm{x}$ & $\mathrm{x}$ \\
Organ of Corti-apex & $\mathrm{x}$ & $\mathrm{x}$ & $\mathrm{x}$ & $\mathrm{x}$ \\
Organ of Corti-base & $\mathrm{x}$ & $\mathrm{x}$ & $\mathrm{x}$ & $\mathrm{x}$ \\
IHCs-apex & $\mathrm{x}$ & $\mathrm{x}$ & & $\mathrm{x}$ \\
IHCs-base & $\mathrm{x}$ & $\mathrm{x}$ & $\mathrm{x}$ & \\
OHCs-apex & $\mathrm{x}$ & & & $\mathrm{x}$ \\
OHCs-base & & & & \\
\hline
\end{tabular}

was found in OHCs. We also observed similar gradients of KCNQ4 expression in rat and gerbil SGNs and cochlear hair cells (Fig. 5G, H,J,K), thus expanding our initial findings (Beisel et al., 2000). KCNQ4 was also observed in vestibular type I and type II hair cells and vestibular ganglion neurons (data not shown). Our data demonstrate that KCNQ4 is topologically expressed in both inner ear hair cells and sensory afferent neurons and is not restricted to a specific hair cell type.

Because frequency representation in the rodent organ of Corti 


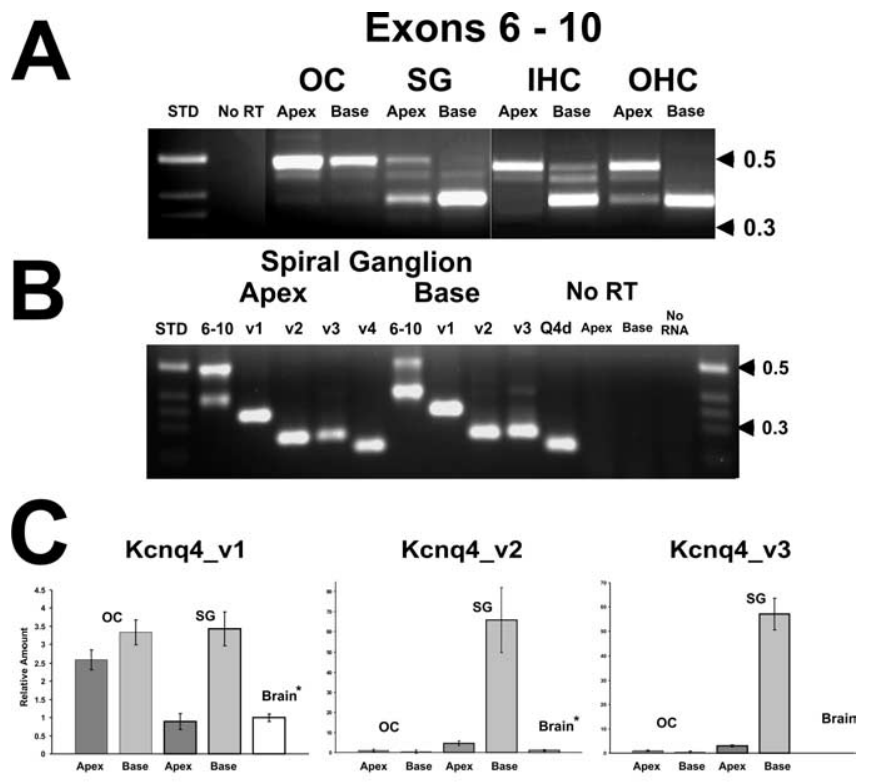

D

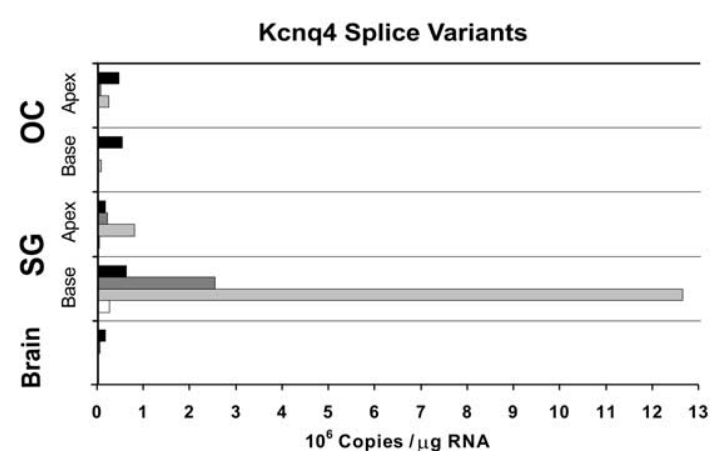

Figure 3. Regional and cellular differences in Kcnq4 transcripts in the cochlea. $\boldsymbol{A}, \mathrm{RT}-\mathrm{PCR}$ to amplify Kcnq4 fragments representing exons $6-10$ was done to determine use of exons 9-11 in cochlear tissue from 5- to 6-week-old mice. Apical and basal samples were obtained and represented fragments of the organ of Corti, spiral ganglion, and $O C$ fragments containing $\mathrm{IHCS}$ and $\mathrm{OHCs}$. No RT, Absence of reverse transcriptase. $\boldsymbol{B}, \mathrm{RT}-\mathrm{PCR}$ analyses were performed using splice variant-specific primer sets for the Kcnq4_v1,Kcnq4_v2,Kcnq4_v3, and Kcnq4_v4 transcript variants from apical and basal fragments of the spiral ganglion. Positive controls were exon 6 and exon 10 primer sets, and negative controls included the absence of reverse transcriptase and total RNA. A 1 kb ladder (Invitrogen) was used as a standard size marker (STD), and the corresponding kilobase lengths are indicated in $\boldsymbol{A}$ and $\boldsymbol{B}$. C, QPCRs were done using primer and probe sets specific for each of the Kcnq4_v1,Kcnq4_v2,Kcnq4_v3, and Kcnq4_v4 alternatively spliced variants, and their relative amounts to brain $\left(^{*}\right)$ were determined. The presence of the Kcnq4_v4 transcripts was detectable only after 55-60 cycles of amplification (data not shown). Apical and basal samples were obtained and represented fragments of the organ of Corti, and the spiral ganglion was compared with levels present in mouse brain total RNA. Error bars represent SD. D. The absolute levels of each transcript variant, Kcnq4_v1 (black), Kcnq4_v2 (dark gray), Kcnq4_v3 (light gray), and Kcnq4_v4 (white), for samples of the organ of Corti and spiral ganglion and are represented by tissue fragments harvested from the cochlear apex and base. $0 C$, Organ of Corti; $S G$, spiral ganglion.

changes from P21 to P35 (Müller, 1991a,b; Müller et al., 2005), we explored whether alternations occurred in ion-channel expression during this final maturation age that could establish a stable and static expression pattern in older mice. QPCR analyses demonstrated that the transcript levels of Kcnq4 in the organ of Corti had decreased by $\sim 30-50 \%$ in the middle and basal turns (Fig. 6A). There are quantitative differences in the levels of the Kcnq4 splice forms at various postnatal stages as well as along the length of the organ of Corti (Fig. $6 \mathrm{~B}$ ). Throughout the length of the organ of Corti, the levels of Kcnq4_v1 are not significantly
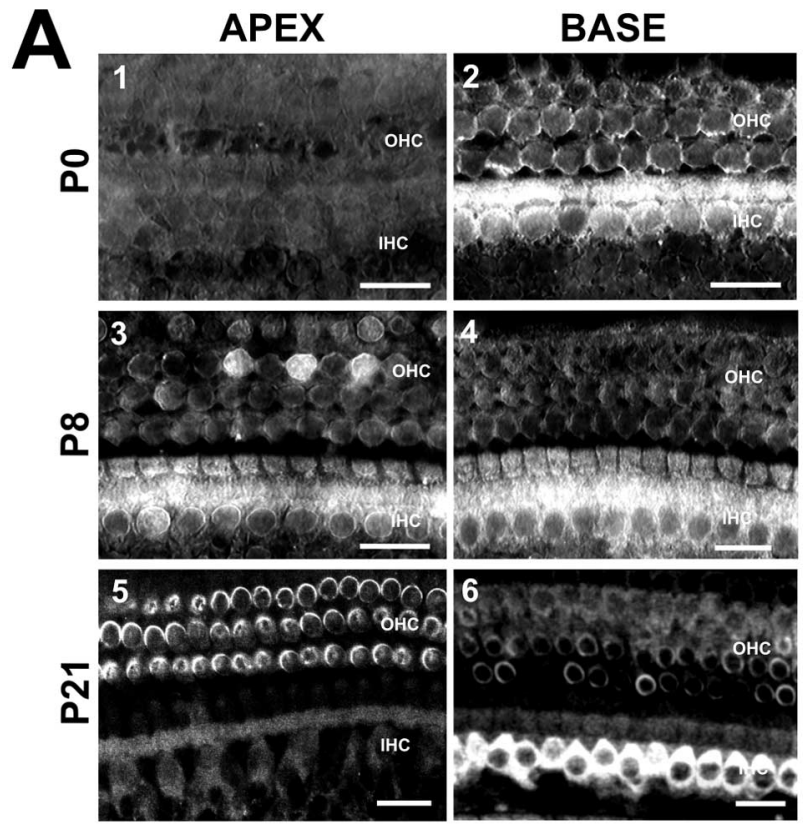

B

Age

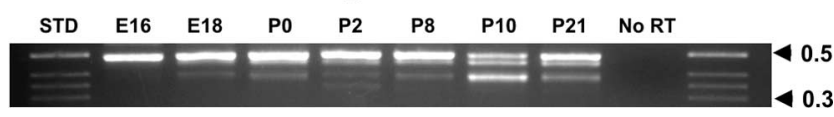

Figure 4. Developmental expression of Kcnq4. $\boldsymbol{A}$, Comparisons of the apical $(1,3,5)$ and basal hook $(2,4,6)$ regions for anti-KCNQ4 immunohistochemistry of the organ of Corti from postnatal P0 $(1,2), P 8(3,4)$, and immunofluorescence of P21 $(5,6)$ mice. Magnification, $600 \times$; scale bar, $10 \mu \mathrm{m}$. $\boldsymbol{B}$, Developmental regulation of $K c n q 4$ splice variants in the mouse cochlea from embryonic (E16, E18) and postnatal (P0, P2, P8, P10, P21) animals were examined using the exon 6 -10 primer set. A $1 \mathrm{~kb}$ ladder (Invitrogen) was used as a standard size marker (STD), and the corresponding kilobase lengths are indicated. No RT, Absence of reverse transcriptase.

different between P0 and P21. At P120, the levels are higher in the apical turn but lower in both the middle and basal turns. The remaining three splice forms (Kcnq4_v2, Kcnq4_v3, and Kcnq4_v4) show relatively higher levels of expression at P21 in the basal and middle regions of the organ of Corti. These levels drop off considerably by P120. Kcnq4_v1 was found to be the predominant variant regardless of age and location in the organ of Corti. However, the ratio in the levels of Kcnq4_v1 compared with the other three splice variants differed considerably at various postnatal stages as well as along the length of the organ of Corti. The total amount of Kcnq4_v3 and Kcnq4_v2 transcripts at P21 exceeds the amount of Kcnq4_v1 in the middle and basal regions. Furthermore, there is a gradient in the levels of Kcnq4_v2 and Kcnq4_v3 with the highest levels in the basal region and the lowest levels in the apical region. No apparent changes were observed in the Kcnq4 expression patterns between P21 and P35 cochlea, except by P35 when the IHCs in the apical tip had obtained the adult pattern of KCNQ4 expression. In P120 mice, KCNQ4 levels appeared to have increased in cochlear hair cells in which the most obvious changes, observed in IHCs, were in the middle and basal turns (Fig. 6C). However, the disparity in Kcnq4 transcript and protein levels in the P120 mice suggests a slower rate of turnover of the KCNQ4 protein in the cochlear hair cells. This retention suggests a changing homoeostasis of protein and may reflect a continuation of the developmental upregulation and expression topology, at a much slower pace. 


\section{Discussion}

KCNQ4_v3 variant related to PHFHL

PHFHL in DFNA2 patients was thought initially to be related to KCNQ4 expression in OHCs (Kubisch et al., 1999). Our data show that Kcnq4 is not restricted to the auditory system (Kharkovets et al., 2000; Oliver et al., 2003). We demonstrate that splice variant Kcnq4_v3 is restricted primarily to the cochlea, with the highest expression in the basal spiral ganglion and IHCs, corresponding to HFHL in DFNA2 patients. Longitudinal differences exhibit both qualitative and quantitative changes in Kcnq4 variant use and as such should provide a range of homotetrameric and heterotetrameric channels that differ from the base to the apex. Such longitudinal differences may also integrate with the longitudinal tonotopic gradient to facilitate the increasing apical to basal frequencyspecific functional demands on the cochlear hair cells and afferent sensory neurons with overall ion-channel density being highest in the base (Housley and Ashmore, 1992; Mammano et al., 1995). Clearly, the expression of the Kcnq4_v3 transcript in the base is unlike that of the other Kcnq4 splice variants.

In contrast, Kcnq4_v1 is ubiquitously expressed, albeit at low levels, presenting a conundrum, especially because mutated KCNQ4 is not accompanied by any additional symptoms. This raises the question of the significance of the widespread and ubiquitous presence of Kcnq4_v1. Modulation of KCNQ4 channel activity can be initiated by changes in cell volume, in which cell swelling activates these channels and hyperosmotic conditions are inhibitory (Hougaard et al., 2004). KCNQ1 also exhibits a similar property of cell volume regulation (Sogaard et al., 2001). This rapid cell volume homeostasis is presumed to be mediated by a large number of transporters and channels (Wehner et al., 2003), negating any pathological impact from dysfunctional KCNQ4_v1 homomeric channels.

The predominance of Kcnq4_v1 in the apex questions its putative role in HFHL.

KCNQ4 is retained in the cytoplasm of apical IHCs (Fig. 6B), which is consistent with data from Kcnq4_v1-transformed human embryonic kidney cells (Feng et al., 2004) and suggests that the majority of KCNQ4_v1 channels or subunits are held in the intracellular compartment. Although two other Kcnq4 splice variants, Kcnq4_v2 and Kcnq4_v4, are expressed in the inner ear, they represent rare to limited components in KCNQ4 channel composition. Yet, all four KCNQ4 variants likely contribute to variation of M-type conductance properties (Kubisch et al., 1999; Oliver et al., 2003). Therefore, the Kcnq4_v3 variant and its associated basal homomeric channels in IHCs and sensory neurons
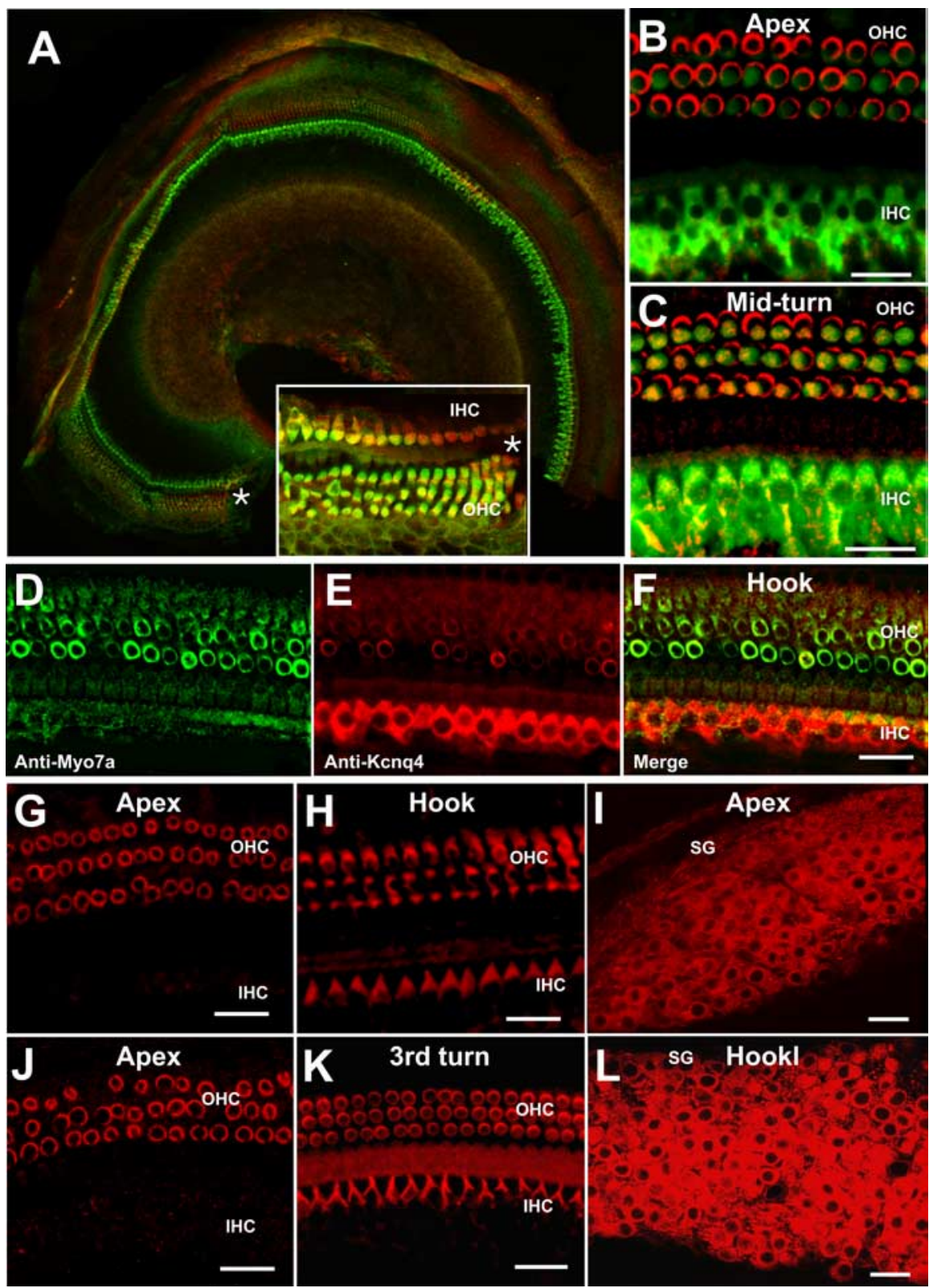

Figure 5. Immunofluorescence analyses of KCNQ4 cochlear expression. The expression pattern of Kcnq4 in P21 animals was done using anti-KCNQ4 peptide affinity-purified rabbit Igs (red signal) and mouse anti-myosin 7a monoclonal lgs (green signal) in apex. Inset $\left({ }^{*}\right)$, The last vestiges of developmental upregulation of $K$ cnq 4 in IHCs at the very apical tip $(600 \times)$. High-power images of the organ of Corti from the apex $(\boldsymbol{B})$, the middle region $(\boldsymbol{C})$, and basal hook region $(\boldsymbol{D})$ (the green channel, anti-myosin 7a; $\boldsymbol{E}$, the basal hook region $(\boldsymbol{H})$, the gerbil apex $(\boldsymbol{J})$, and the third cochlear turns $(\boldsymbol{K})$. KCNQ4 immunodetection of mouse spiral ganglion (SG) samples from the apex $(\boldsymbol{I})$ and basal hook region $(\boldsymbol{L})$ are shown. Scale bar, $10 \mu \mathrm{m}$.

are likely to be the major contributors to the KCNQ4-mediated PHFHL in the inner ear.

\section{Functional implications of differential expression of KCNQ4 variants}

KCNQ4 currents may contribute substantially in establishing the resting membrane potential of IHCs and in so doing control the intracellular $\left[\mathrm{Ca}^{2+}\right]$ (Oliver et al., 2003). Moreover, several reports have suggested that $\mathrm{Ca}^{2+}$ may regulate KCNQ channels by reducing the magnitude of the current (Gamper and Shapiro, 2003). The relationship between the conductance of KCNQ4 currents and intracellular $\left[\mathrm{Ca}^{2+}\right]$ may result in a positive feedback 


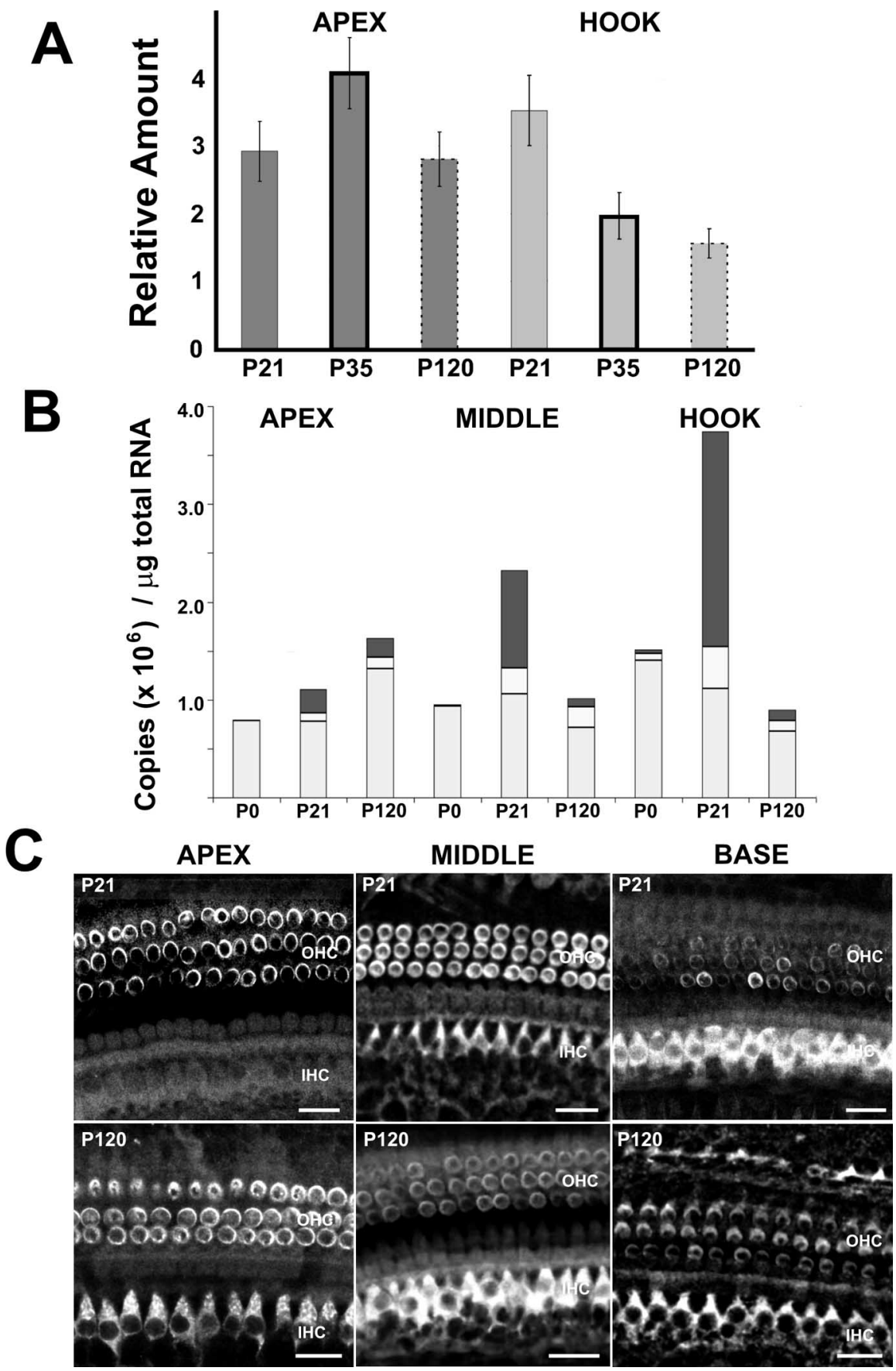

Figure 6. Changing expression levels of $K c n q 4$ in aging mice. $A$, Relative concentrations of $K c n q 4$ transcripts were determined by QPCR analyses of the dissected apex (dark gray) and basal hook region (light gray) of the organ of Corti from P21, P35, and P120 mice. The relative amounts of $K c n q 4$ transcripts were determined using concentrations in the brain as the standard. Error bars represent SD. B, QPCRs were done using primer and probe sets specific for each of the Kcnq4_v1 (light gray), Kcnq4_v2 (white), Kcnq4_v3 (dark gray), and Kcnq4_v4 alternatively spliced variants. Copies of transcripts per micrograms of total RNA were estimated. Kcnq4_v4 levels were insignificant (data not shown). Samples from the apex, middle turn, and basal hook region of the organ of Corti were obtained, and total RNA from the representative fragments were analyzed. C, Comparisons of the apical, middle, and basal turns for anti-KCNQ4 immunodetection of the organ of Corti from P21 and P129 mice. The gain for the P120 base image was decreased to permit cytological imaging of the IHCs. Magnification, 600X; scale bar, $10 \mu \mathrm{m}$.

Gamper and Shapiro, 2003). KCNQ4 variants in the inner ear have two distinct $\mathrm{CaM}$ binding sites. KCNQ4_v2 has one extra CaM-binding motif, FxxxxxxFxxxxxW (1-8-14-type CaM-binding motif), raising the possibility that KCNQ4_v2 is modulated differently. The $\mathrm{C}$ termini of KCNQ channels are also a substrate for protein kinase A (PKA) phosphorylation, and application of 8-bromo-cAMP or the catalytic PKA subunit shifts the voltagedependent activation of KCNQ4 currents by approximately $-20 \mathrm{mV}$ (Kurokawa et al., 2004; Chambard and Ashmore, 2005) and may serve as a regulatory site for not only the functional modulation but also for assembly of the channels. Also, KCNQ4 channels are localized at the basal pole of the hair cell, where postsynaptic density (PSD) protein labeling is found (Davies et al., 2001). An internal PDZ (PSD-95/Discs large/zona occludens-1)binding motif (KTXXXI) was identified near the KCNQ4 C terminus. PSD-95 was shown to induce clustered expression of $\mathrm{K}^{+}$channels on the cell surface (Kim and Sheng, 1996). These studies are consistent with preliminary reports suggesting that KCNQ4 variants in heterologous expression systems have different membrane expression levels (Feng et al., 2004). Variations in the amino acid sequences of the KCNQ4_v1-v4 occur near the beginning of the cytoplasmic carboxy tail. Because the expression of the variants differs along the cochlear longitudinal axis, this may translate into the functional differences in the current phenotype. Thus, KCNQ4 variant homomeric and heteromeric channels in cochlear neurosensory and neuronal cells may have important electrophysiological implications.

\section{KCNQ4 pathology-mediated by SGNs and IHCs}

Defective KCNQ4 subunits in the afferent signal transmission of the peripheral and/or central auditory system could mediate PHFHL alone or in combination (Beisel et al., 2000; Kharkovets et al., 2000; Oliver et al., 2003). The basal turn and hook regions are the regions of highfrequency tonotopic representation. The HFHL in DFNA2 patients lead us to predict that KCNQ4 gradients should be highest in the base. Our hypothesis is that KCNQ4-mediated PHFHL is a direct re-

mechanism that could produce an untoward hair cell depolarization. $\mathrm{Ca}^{2+} /$ calmodulin (CaM) may bind to at least two putative CaM-binding motifs in the $\mathrm{C}$ termini of KCNQ family members, namely IQxxxRGxxxxR and a $\mathrm{Ca}^{2+}$-dependent CaM-binding motif, $x x V x x x I x x x F$ (1-5-10-type CaM-binding motif) to alter the current (Wen and Levitan, 2002; Yus-Najera et al., 2002; sult of a dysfunctional electrical signaling of basal turn/hook IHCs and SGNs, impairing their function as effective signal transducers (Beisel et al., 2000). Oliver and colleagues (2003) suggested that the dominant-negative KCNQ4 causes pathogenesis by destabilization of the cellular resting potential. The base $>$ apex longitudinal gradients of Kcnq4 transcript levels (Beisel et 
al., 2000) is also supported here by parallel longitudinal changes in protein levels in IHCs and SGNs. Because there is 10-20 times the amount of transcripts present in SGNs in the basal hook region of the cochlea compared with IHCs, it is possible that dysfunctional sensory neurons are the target. Ten or more SGNs converge on a single IHC (Spoendlin and Schrott, 1988; Liberman et al., 1990; Ryugo, 1992). There is also a differential longitudinal gradient with three times the number of neurons converging on the basal versus apical IHCs (Ryugo, 1992). We propose that dysfunction of both the IHC and SGN is the primary pathogenic target of KCNQ4-mediated PHFHL, thereby distinguishing DFNA2 from other inner ear channelopathies.

\section{Mutational load in disease progression}

KCNQ4-mediated PHFHL varies in the time of onset, severity of hearing loss, and rate of progression. It is our premise that accumulation of defective proteins over time negatively impacts cochlear function, leading to hair cell deterioration and eventual degeneration of the cochlea, here referred to as mutational load. Mutational load may be a mechanism that influences the course and outcome of the associated auditory pathogenesis. An example of mutational load is one in which accumulation of mutated mitochondrial DNA can lead to hearing loss with the clinical features varying in the age of onset, spatiotemporal rate of progression, and severity (Fischel-Ghodsian, 2003). Variations in the clinical phenotype of KCNQ4-mediated PHFHL are known (De Leenheer et al., 2002; Topsakal et al., 2005). The severity and rate of progression can vary within a pedigree and among families carrying the same mutations. Besides epigenetic or modifier gene effects, another viable explanation may be derived from the agerelated increase in KCNQ4 observed in the P120 mice, in which an increasing load of mutated or defective protein may lead to progressive cellular dysfunction.

Both genetic and mutational loads can have an impact on the phenotype-genotype relationships. An excellent example is Romano-Ward or long QT and Jervell and Lange-Nielson syndromes, mediated by KCNQ1 and KCNE1 (Chouabe et al., 1997; Neyroud et al., 1997; Tyson et al., 1997). In vitro studies have demonstrated that the quantities of intact wild-type channels are important, in which the greater the ratio of mutant to normal subunits, the higher the likelihood of abnormalities in the $I_{\mathrm{Ks}}$ currents (Chouabe et al., 1997; Priori et al., 1998). In part, the low penetrance or "forme fruste" observed in Romano-Ward syndrome could be a function of the degree by which the dominantnegative mutation disrupts $I_{\mathrm{Ks}}$ conductances (Priori et al., 1999). Thus, the severity of both cardiac and auditory clinical features is dependent on the mutant allele itself, the ratio of wild-type to mutant protein, the ratio of normal to dysfunctional channel, and gene dosage (Ning et al., 2003). Thus, gene dosage and mutational load can directly impact on the severity of the resulting cardiac and inner ear defects, thereby creating a wide spectrum of clinical presentations.

In summary, our data suggest that the high levels of Kcnq4_v3 in both basal IHCs and SGNs mediate DFNA2 and result in dysfunctional electrical signaling. We suggest that the initial PHFHL pathogenesis is mediated by dysfunctional IHCs and SGNs, in which cell survival is reflected by their functional durability along the length of the tonotopic gradient and the rate of accumulation of mutated KCNQ4 subunits. These differences could also impact the rate of progression and severity of HFHL in KCNQ4mediated disease. To test the hypothesis of mutational load in DFNA2 progression, we are presently constructing genetically altered mouse lines carrying a humanized dominant-negative mutation in the mouse Kcnq4 gene expressed in IHC, sensory neurons, or both.

\section{References}

Barritt LC, Fritzsch B, Beisel KW (1999) Characterization of G-protein betagamma expression in inner ear. Brain Res Mol Brain Res 68:42-54.

Beisel KW, Fritzsch B (2003) Diverse and dynamic expression patterns of voltage-gated ion channel genes in rat cochlear hair cells. In: Biophysics of the cochlear from molecules to models (Gummer AW, ed), pp 191-193. Singapore: World Scientific Publishing.

Beisel KW, Nelson NC, Delimont DC, Fritzsch B (2000) Longitudinal gradients of KCNQ4 expression in spiral ganglion and cochlear hair cells correlate with progressive hearing loss in DFNA2. Brain Res Mol Brain Res 82:137-149.

Beisel KW, Shiraki T, Morris KA, Pompeia C, Kachar B, Arakawa T, Bono H, Kawai J, Hayashizaki Y, Carninci P (2004) Identification of unique transcripts from a mouse full-length, subtracted inner ear cDNA library. Genomics 83:1012-1023.

Boettger T, Hubner CA, Maier H, Rust MB, Beck FX, Jentsch TJ (2002) Deafness and renal tubular acidosis in mice lacking the $\mathrm{K}-\mathrm{Cl}$ cotransporter Kcc4. Nature 416:874-878.

Chambard JM, Ashmore JF (2005) Regulation of the voltage-gated potassium channel KCNQ4 in the auditory pathway. Pflügers Arch 450:34-44.

Chouabe C, Neyroud N, Guicheney P, Lazdunski M, Romey G, Barhanin J (1997) Properties of KvLQT1 K ${ }^{+}$channel mutations in Romano-Ward and Jervell and Lange-Nielsen inherited cardiac arrhythmias. EMBO J 16:5472-5479.

Davies C, Tingley D, Kachar B, Wenthold RJ, Petralia RS (2001) Distribution of members of the PSD-95 family of MAGUK proteins at the synaptic region of inner and outer hair cells of the guinea pig cochlea. Synapse 40:258-268.

De Leenheer EM, Huygen PL, Coucke PJ, Admiraal RJ, van Camp G, Cremers CW (2002) Longitudinal and cross-sectional phenotype analysis in a new, large Dutch DFNA2/KCNQ4 family. Ann Otol Rhinol Laryngol 111:267-274.

Delpire E, Lu J, England R, Dull C, Thorne T (1999) Deafness and imbalance associated with inactivation of the secretory $\mathrm{Na}-\mathrm{K}-2 \mathrm{Cl}$ co-transporter. Nat Genet 22:192-195.

Dixon MJ, Gazzard J, Chaudhry SS, Sampson N, Schulte BA, Steel KP (1999) Mutation of the Na-K-Cl co-transporter gene Slc12a2 results in deafness in mice. Hum Mol Genet 8:1579-1584.

Feng W, Nie L, Zhang Y, Vazquez AE, Morris K, Beisel K, Yamoah EN (2004) Functional properties of inner ear-specific KCNQ4 channels and the significance of alternative splicing. Paper presented at 27th Annual Meeting of the Association for Research in Otolaryngology, Daytona Beach, FL, February.

Fischel-Ghodsian N (2003) Mitochondrial deafness. Ear Hear 24:303-313.

Flagella M, Clarke LL, Miller ML, Erway LC, Giannella RA, Andringa A, Gawenis LR, Kramer J, Duffy JJ, Doetschman T, Lorenz JN, Yamoah EN, Cardell EL, Shull GE (1999) Mice lacking the basolateral Na-K-2Cl cotransporter have impaired epithelial chloride secretion and are profoundly deaf. J Biol Chem 274:26946-26955.

Fritzsch B, Farinas I, Reichardt LF (1997) Lack of neurotrophin 3 causes losses of both classes of spiral ganglion neurons in the cochlea in a regionspecific fashion. J Neurosci 17:6213-6225.

Gamper N, Shapiro MS (2003) Calmodulin mediates $\mathrm{Ca}^{2+}$-dependent modulation of M-type $\mathrm{K}^{+}$channels. J Gen Physiol 122:17-31.

Hougaard C, Klaerke DA, Hoffmann EK, Olesen SP, Jorgensen NK (2004) Modulation of KCNQ4 channel activity by changes in cell volume. Biochim Biophys Acta 1660:1-6.

Housley GD, Ashmore JF (1992) Ionic currents of outer hair cells isolated from the guinea-pig cochlea. J Physiol (Lond) 448:73-98.

Jentsch TJ (2000) Neuronal KCNQ potassium channels: physiology and role in disease. Nat Rev Neurosci 1:21-30.

Judice TN, Nelson NC, Beisel CL, Delimont DC, Fritzsch B, Beisel KW (2002) Cochlear whole mount in situ hybridization: identification of longitudinal and radial gradients. Brain Res Brain Res Protoc 9:65-76.

Kharkovets T, Hardelin JP, Safieddine S, Schweizer M, El-Amraoui A, Petit C, Jentsch TJ (2000) KCNQ4, a K ${ }^{+}$channel mutated in a form of dominant deafness, is expressed in the inner ear and the central auditory pathway. Proc Natl Acad Sci USA 97:4333-4338.

Kim E, Sheng M (1996) Differential $\mathrm{K}^{+}$channel clustering activity of 
PSD-95 and SAP97, two related membrane-associated putative guanylate kinases. Neuropharmacology 35:993-1000.

Kros CJ, Ruppersberg JP, Rusch A (1998) Expression of a potassium current in inner hair cells during development of hearing in mice. Nature 394:281-284.

Kubisch C, Schroeder BC, Friedrich T, Lutjohann B, El-Amraoui A, Marlin S, Petit C, Jentsch TJ (1999) KCNQ4, a novel potassium channel expressed in sensory outer hair cells, is mutated in dominant deafness. Cell 96:437-446.

Kurokawa J, Motoike HK, Rao J, Kass RS (2004) Regulatory actions of the A-kinase anchoring protein Yotiao on a heart potassium channel downstream of PKA phosphorylation. Proc Natl Acad Sci USA 101:16374-16378.

Liberman MC, Dodds LW, Pierce S (1990) Afferent and efferent innervation of the cat cochlea: quantitative analysis with light and electron microscopy. J Comp Neurol 301:443-460.

Mammano F, Kros CJ, Ashmore JF (1995) Patch clamped responses from outer hair cells in the intact adult organ of Corti. Pflügers Arch 430:745-750.

Marcotti W, Kros CJ (1999) Developmental expression of the potassium current IK,n contributes to maturation of mouse outer hair cells. J Physiol (Lond) 520:653-660.

Marcotti W, Johnson SL, Holley MC, Kros CJ (2003) Developmental changes in the expression of potassium currents of embryonic, neonatal and mature mouse inner hair cells. J Physiol (Lond) 548:383-400.

Morris KA, Snir E, Pompeia C, Koroleva IV, Kachar B, Hayashizaki Y, Carninci P, Soares MB, Beisel KW (2005) Differential expression of genes within the cochlea as defined by a custom mouse inner ear microarray. J Assoc Res Otolaryngol 6:75-89.

Müller M (1991a) Frequency representation in the rat cochlea. Hear Res 51:247-254

Müller M (1991b) Developmental changes of frequency representation in the rat cochlea. Hear Res 56:1-7.

Müller M, von Hunerbein K, Hoidis S, Smolders JW (2005) A physiological place-frequency map of the cochlea in the $\mathrm{CBA} / \mathrm{J}$ mouse. Hear Res 202:63-73.

Neyroud N, Tesson F, Denjoy I, Leibovici M, Donger C, Barhanin J, Faure S, Gary F, Coumel P, Petit C, Schwartz K, Guicheney P (1997) A novel mutation in the potassium channel gene KVLQT1 causes the Jervell and Lange-Nielsen cardioauditory syndrome. Nat Genet 15:186-189.

Ning L, Moss AJ, Zareba W, Robinson J, Rosero S, Ryan D, Qi M (2003) Novel compound heterozygous mutations in the KCNQ1 gene associated with autosomal recessive long QT syndrome (Jervell and Lange-Nielsen syndrome). Ann Noninvasive Electrocardiol 8:246-250.

Oliver D, Knipper M, Derst C, Fakler B (2003) Resting potential and submembrane calcium concentration of inner hair cells in the isolated mouse cochlea are set by KCNQ-type potassium channels. J Neurosci 23:2141-2149.

Petit C, Levilliers J, Hardelin JP (2001) Molecular genetics of hearing loss. Annu Rev Genet 35:589-646.

Priori SG, Schwartz PJ, Napolitano C, Bianchi L, Dennis A, De Fusco M, Brown AM, Casari G (1998) A recessive variant of the Romano-Ward long-QT syndrome? Circulation 97:2420-2425.

Priori SG, Napolitano C, Schwartz PJ (1999) Low penetrance in the long-QT syndrome: clinical impact. Circulation 99:529-533.

Pujol R, Lavigne-Rebillard M, Lenoir M (1998) Development of sensory and neural structures in the mammalian cochlea. In: Development of the auditory system (Rubel EW, Popper AN, Fay RR, eds), pp 146-192. New York: Springer.

Ryugo DK (1992) The auditory nerve, peripheral innervation, cell body morphology, and central projections. In: The mammalian auditory pathway: neuroanatomy, Springer handbook of auditory research (Webster DB, Popper AN, Fay RR, eds), pp 23-65. New York: Springer.

Sogaard R, Ljungstrom T, Pedersen KA, Olesen SP, Jensen BS (2001) KCNQ4 channels expressed in mammalian cells: functional characteristics and pharmacology. Am J Physiol Cell Physiol 280:C859-C866.

Spoendlin H, Schrott A (1988) The spiral ganglion and the innervation of the human organ of Corti. Acta Otolaryngol 105:403-410.

Steel KP, Kros CJ (2001) A genetic approach to understanding auditory function. Nat Genet 27:143-149.

Topsakal V, Pennings RJ, te Brinke H, Hamel B, Huygen PL, Kremer H, Cremers CW (2005) Phenotype determination guides swift genotyping of a DFNA2/KCNQ4 family with a hot spot mutation (W276S). Otol Neurotol 26:52-58.

Tyson J, Tranebjaerg L, Bellman S, Wren C, Taylor JF, Bathen J, Aslaksen B, Sorland SJ, Lund O, Malcolm S, Pembrey M, Bhattacharya S, BitnerGlindzicz M (1997) IsK and KvLQT1: mutation in either of the two subunits of the slow component of the delayed rectifier potassium channel can cause Jervell and Lange-Nielsen syndrome. Hum Mol Genet 6:2179-2185.

Wehner F, Olsen H, Tinel H, Kinne-Saffran E, Kinne RK (2003) Cell volume regulation: osmolytes, osmolyte transport, and signal transduction. Rev Physiol Biochem Pharmacol 148:1-80.

Wen H, Levitan IB (2002) Calmodulin is an auxiliary subunit of KCNQ2/3 potassium channels. J Neurosci 22:7991-8001.

Wong WH, Hurley KM, Eatock RA (2004) Differences between the negatively activating potassium conductances of mammalian cochlear and vestibular hair cells. J Assoc Res Otolaryngol 5:270-284.

Yus-Najera E, Santana-Castro I, Villarroel A (2002) The identification and characterization of a noncontinuous calmodulin-binding site in noninactivating voltage-dependent KCNQ potassium channels. J Biol Chem 277:28545-28553. 